\title{
Clinical Exercise Physiology and Health Care
}

\author{
Zhou Shi* \\ School of Health and Human Science, Southern Cross University, Australia \\ *Corresponding author: Zhou Shi, School of Health and Human Science, Southern Cross University, NSW 2480, Australia
}

Submission: 眥 February 24, 2018; Published: 每 February 27, 2018

\section{Editorial}

The roles of physical activity, including exercise, in improvement of fitness and health, and prevention and treatment of many health conditions have been well recognized. Physical inactivity has been identified by the World Health Organization as one of the major risks of mortality [1]. Based on the evidence from research and professional practice, governments and professional bodies have published guidelines for adequate levels of physical activity in daily life [2-4]. American College of Sports Medicine (ACSM) and American Medical Association (AMA) jointly introduced the concept of "Exercise is Medicine" in 2007, encouraging primary care physicians and other health care providers to include physical activity as a standard part of medical treatment and patient care [5]. The concept and practice of "Exercise is Medicine" have been adopted in more than 30 countries globally.

Exercise professionals play a fundamental role in promotion and delivery of exercise programs in the community. Clinical exercise physiology (CEP) is relatively new profession in health care. CEP is defined by the Clinical Exercise Physiology Association of the United States of America as "a healthcare professional who is trained to work with patients with chronic diseases where exercise training has been shown to be of therapeutic benefit, including but not limited to cardiovascular disease, pulmonary

disease, and metabolic disorders" [6]. Australia has created an excellent model for accreditation of exercise professionals. CEP has been recognized by the Medicare system of Australia as one of the allied health professions since 2006. Exercise and Sports Science Australia (ESSA) is the peak professional body in Australia. ESSA has established an accreditation system for exercise scientists (using exercise to improve health, well-being and fitness), clinical

exercise physiologists (using exercise to help manage chronic conditions and injuries), sport scientists (using exercise to improve sporting performance) and high performance managers (managing a range of performance services for elite sport) [7]. ESSA has also established an accreditation system for relevant university courses to ensure quality training of these exercise professionals.

There are obviously different foci of health care providers as well as some overlaps between the services, for example, between CEP, sports medicine and physiotherapy. Nevertheless, the practice in the services should be based on scientific evidence. A tremendous amount of research in these fields has been published that informs the current practice. We encourage more research work with interdisciplinary approaches to be published in Research Investigations in Sports Medicine, for even better practice and services to the community by exercise and sports medicine professionals.

\section{References}

1. World HealthOrganization (2010) Global recommendations on physical activity for health. Retrived February 2018, http://www.who.int/ dietphysicalactivity/factsheet_recommendations/en/

2. Australian Government Department of Health (2017) Australia's Physical Activity and Sedentary Behaviour Guidelines. Retrived February 2018, http://www.health.gov.au/internet/main/publishing.nsf/Content/ health-pubhlth-strateg-phys-act-guidelines

3. United Kindom Department of Health and Social Care (2011) UK physical activity guidelines. Retrived February 2018, https://www.gov. uk/government/publications/uk-physical-activity-guidelines

4. US Department of Health and Human Services (2008) 2008 Physical Activity Guidelines for Americans. Retrived February 2018, https:// health.gov/paguidelines/pdf/paguide.pdf

5. Exercise is Medicine. Retrived February 2018, http://exerciseismedicine. org/about.htm

6. Clinical Exercise Physiology Associate (2008) What is a Clinical Exercise Physiologist? Retrived February 2018, https://www.acsm-cepa.org/ i4a/pages/index.cfm?pageID=3304

7. Exercise and Sports Science Australia. Retrived February 2018, https:// www.essa.org.au/ 
For possible submissions Click Here

Your subsequent submission with Crimson Publishers will attain the below benefits

- High-level peer review and editorial services

- Freely accessible online immediately upon publication

- Authors retain the copyright to their work

- Licensing it under a Creative Commons license

- Visibility through different online platforms

- Global attainment for your research

- Article availability in different formats (Pdf, E-pub, Full Text)

- Endless customer service

- Reasonable Membership services

- Reprints availability upon request

- One step article tracking system 